\title{
Avances en la propagación del aguacate
}

\author{
Mariana Freire Alberti ${ }^{1}$, Bruna do Amaral Brogio ${ }^{1}$, Simone Rodrigues da Silva ${ }^{2}$, \\ Tatiana Cantuarias-Avilés ${ }^{3}$, Claudia Fassio ${ }^{4}$
}

\begin{abstract}
Resumen - Por ser una especie de polinización cruzada y altamente heterocigótica, la multiplicación del aguacate por semilla origina una progenie altamente variable en relación a las características morfológicas y biológicas. Por ese motivo, se hizo relevante la adopción de métodos de propagación más eficientes, que resulten en plántulas de mejor calidad en términos de producción y resistencia a enfermedades. La injertación es el más utilizado para la propagación comercial de aguacate en los principales países productores. Originalmente, la implementación de plantaciones de aguacate se realizó a partir de plántulas obtenidas de portainjertos provenientes de semillas, siendo ese método de multiplicación el que aún predomina en Brasil. Sin embargo, tal procedimiento confiere en el campo mucha variabilidad y diferencias de productividad, calidad y vigor entre las plantas. En países que adoptan mayor nivel tecnológico, el portainjerto pasó a ser obtenido a partir de métodos clonales (Frolich y Platt, Brokaw, Allesbeste) asociados a otras técnicas como la etiolación y el anillado de los brotes. La presente revisión bibliográfica tiene como objetivo abordar los principales métodos de propagación utilizados en aguacate, sus avances y la importancia del mejoramiento genético y de las nuevas investigaciones en la obtención de cultivares de portainjerto y copa que atiendan las demandas del mercado.
\end{abstract}

Términos para indexación: Persea americana Mill., injerto, portainjerto clonal, etiolación, anillado.

\section{Advances in propagation of avocado}

Corresponding author: srsilva@usp.br

Received: October 27, 2016 Accepted: January 11, 2017

Copyright: All the contents of this journal, except where otherwise noted, is licensed under a Creative Commons Attribution License.

\begin{abstract}
Being the avocado a highly cross-pollinated and heterozygous species, its multiplication from seeds produces a highly variable progeny in relation to the morphological and biological characteristics of the parents. Therefore, the adoption of more efficient propagation methods for obtaining higher quality seedlings in terms of production and disease resistance became relevant. Scion grafting onto a seedling rootstock is mostly used in the commercial propagation of avocado trees in Brazil and in the main producing countries. However, such a procedure confers great variability and differences in fruit yield and quality and in vigor among the plants in the field. In countries with a higher technological level, the rootstock has been obtained by clonal methods (Frolich and Platt, Brokaw, Allesbeste), associated with other techniques such as etiolation and girdling. The present literature review describes the main propagation methods currently used for avocado, their advances and the importance of breeding and new research techniques on the obtention of new rootstocks and scion cultivars that shall meet the market demands.

Index terms: Persea americana Mill., grafting, clonal rootstock, etiolation, girdling.
\end{abstract}




\section{Introducción}

Las tres razas hortícolas del aguacate - mexicana (Persea americana var. drymifolia, $\mathrm{M})$, guatemalteca $(P$. americana var. guatemalensis, $\mathrm{G})$ y antillana $(P$. americana var. americana, A) presentan diferencias en la sensibilidad a las condiciones ambientales de temperaturas extremas, sequía, exceso o déficit de precipitación (SCHAFFER et al., 2013; WOLSTENHOLME, 2013), salinidad, alcalinidad y pobre aireación del suelo, factores que pueden causar estrés e impedir el desarrollo del sistema radicular (SALAZAR-GARCÍA et al., 2013; WOLSTENHOLME, 2013), con el consecuente efecto en el desarrollo de la parte aérea y la productividad (SCHAFFER et al., 2013).

También son descritas como limitaciones en la producción del aguacate la alternancia en la producción (MICKELBART et al., 2012), el vigor y, principalmente, la presencia de Phytophthora cinnamomi Rands (CASTRO et al., 2007; SCHAFFER et al., 2013) un pseudohongo de la Clase Oomycetes y del Reino Chromista (MASSOLA; KRUGNER, 2011), responsable por la pudrición radicular y que afecta el desarrollo, producción y longevidad de las plantas en los principales países productores de aguacate (KROON et al., 2012) limitando su cultivo (SCHAFFER et al., 2013; ANDRADE-HOYOS et al., 2015). Inicialmente se observa el oscurecimiento de las raicillas más nuevas, el cual evoluciona para un proceso de descomposición que puede avanzar hacia las raíces más viejas (BEDENDO, 2011). La parte aérea del árbol se presenta marchita, clorótica, con hojas pequeñas, deshoja intensa, ramas secas, frutos pequeños y muerte de los punteros, pudiendo ocurrir la muerte de la planta.

Como el ataque del patógeno a la raíz afecta plantas de todas las edades pudiendo llevarlas a la muerte, debido a que las raíces necróticas no absorben agua y nutrimentos (SALATA; SAMPAIO, 2008), es de suma importancia prevenir el problema, utilizando plantas de calidad, materiales genéticos resistentes o tolerantes y técnicas culturales que prevengan, minimicen $\mathrm{y} / \mathrm{o}$ controlen la enfermedad (SMITH et al., 2011).

En ese contexto, es importante destacar los métodos de propagación para la obtención de plantas clonales de aguacate, resistentes a patógenos de suelo y a condiciones de estrés hídrico y salinidad (CASTRO; FASSIO; 2013a; SCHAFFER et al, 2013). Actualmente, el método más utilizado para la propagación comercial del aguacate en los principales países productores es el injerto de un cultivar sobre un portainjerto oriundo de semillas (DE VILLIERS; ERNST, 2015), o sobre portainjerto clonal (ERNST et al., 2013).

En Brasil, el método de propagación más utilizado es el injerto por enchape o hendidura, introducido por el viverista Walter Beck en 1950, en California, que predomina mundialmente hasta los días de hoy, siendo el portainjerto obtenido de un embrión cigótico por medio del uso de semillas monoembriónicas (SILVEIRA et al., 2004). Tal procedimiento confiere gran variabilidad, diferencias de productividad, calidad y vigor entre las plantas de los pomares (PETRY et al., 2012). En otros países productores de aguacate, como Estados Unidos, Australia, Israel y África del Sur, se adoptan métodos de origen clonal para la obtención de portainjertos (ERNST et al., 2013), dado que las plantas clonales pertenecen a genotipos seleccionados para brindar mayor productividad y mayor tolerancia contra la pudrición radicular causada por Phytophthora, siendo esta última una ventaja importante en los casos de replantío (DE VILLIERS; ERNST, 2015), además de proporcionar uniformidad genética entre las plantas del pomar (CASTRO; FASSIO, 2015).

Considerando que la calidad de la planta a ser establecida en el campo es fundamental para la sostenibilidad de la producción, esta revisión bibliográfica tiene por objetivo abordar los principales métodos de propagación utilizados para el aguacate, sus avances y la importancia del mejoramiento genético y de las nuevas investigaciones en la obtención de cultivares de portainjertos y copas que atiendan las demandas del mercado.

\section{Método tradicional de formación de plantas de aguacate: obtención de portainjertos por semilla e injerto de la variedad - Debido a} la polinización cruzada y al alto grado de heterocigosis de la progenie, existe una gran variabilidad en los portainjertos oriundos de semillas, siendo imposible obtener plantas genéticamente uniformes, condición ideal para la formación de pomares comerciales (GLEESON et al., 2015; PETRY et al., 2012). Por tanto, aunque injertadas, las plantas cuyos portainjertos fueron obtenidos de semillas difieren unas de las otras en tamaño, productividad, calidad de frutos y tolerancia a factores bióticos y abióticos (PETRY et al., 2012).

Debido a la alta segregación genética de los portainjertos obtenidos a partir de semillas, se recomienda que la selección de la planta donadora de semillas se haga en función de su vigor, productividad, calidad y adaptación a las condiciones climáticas locales (CASTRO; FASSIO, 2015), además de la compatibilidad con las variedades que serán injertadas (WHILEY et al., 2007). Sin embargo, no siempre es posible reunir todas las características deseables en un único portainjerto.

Los portainjertos pueden ser obtenidos de cultivares de las razas guatemalteca, mexicana o antillana. En Chile, se utilizan semillas de cultivares de la raza mexicana (CASTRO et al., 2003) para la obtención del portainjerto, mientras que en México se utilizan semillas predominantemente de cultivares criollos, los cuales originan plantas vigorosas y rústicas. En Brasil, los viveristas también optan por la utilización de semillas de 
plantas no injertadas para la obtención de portainjertos rústicos, no existiendo un cultivar definido como fuente de semillas.

Las semillas de aguacate utilizadas para la formación de portainjertos deben ser retiradas de frutos maduros provenientes de plantas sanas. Se recomienda retirar la película que envuelve las semillas (tegumento o testa) que inhibe la germinación, y que las mismas sean sembradas inmediatamente después de su recolección y procesamiento. Antes de la siembra, las semillas pueden ser desinfectadas por inmersión en agua a $49-50^{\circ} \mathrm{C}$, secándolas posteriormente a la sombra, o por tratamiento químico, el cual consiste en la inmersión de las semillas en caldos de fungicidas específicos. Generalmente, la siembra es realizada en bolsas plásticas conteniendo suelo libre de patógenos y plagas, pudiendo adicionarse otras fuentes de nutrientes. Las semillas son dispuestas a $5 \mathrm{~cm}$ de profundidad, tomando el cuidado de colocar la superficie más plana de la semilla para abajo y la más puntiaguda para arriba. Las bolsas son mantenidas en ambiente ventilado y con sombreo moderado, con cerca de $50 \%$ de luminosidad y el riego se realiza cuando es necesario. Para las condiciones de siembra de la mayoría de los viveros, la germinación ocurre entre 30 y 60 días, siendo el injerto realizado a partir del momento en que el tallo alcanza cerca de un centímetro de espesura, a una altura de aproximadamente $20 \mathrm{~cm}$, mostrándose apto para recibir las ramas de la variedad a ser producida comercialmente (BETTIOL NETO; PIO, 2016).

Estudios comprobaron que la escarificación de las semillas de aguacate antes de la siembra es un herramienta eficaz para reducir el tiempo de germinación (WHILEY; WHILEY, 2005), pudiendo ser realizada a través de un corte parcial de los cotiledones en el extremo apical de la semilla. Algunos viveristas también realizan un corte o raspado en la base de la semilla (CASTRO; FASSIO, 2013a).

Para el injerto de la variedad, se utilizan dos métodos. El primero, se trata del injerto por el método 'inglés' o de 'lengüeta', el cual consiste en la eliminación del tallo del portainjerto por medio de un corte en bisel, siendo el mismo tipo de corte también realizado en la rama puntera de la planta madre. El otro método, más utilizado en viveros comerciales, es el injerto por hendidura simple o púa terminal, que consiste en la realización de un corte longitudinal de aproximadamente $3 \mathrm{~cm}$ en el portainjerto, en el que será encajado el puntero de la variedad, cortado en formato de cuña. En ambos casos, se debe fija la región de la unión del portainjerto/copa con una cinta y proteger el injerto con una bolsa plástica, de modo que se evite la deshidratación de la púa o vareta, debiendo permanecer con la bolsa plástica y la cinta por cerca de 30 a 40 días, hasta la brotación de las varetas. Después de ese período, se debe retirar los brotes del portainjerto, realizar tratamientos fitosanitarios, conducir y climatizar progresivamente las plantas, entre otras prácticas de manejo. Aproximadamente de 10 a 12 meses después de la siembra del portainjerto las plantas estarán aptas para ser llevadas al local definitivo de siembra (BETTIOL NETO; PIO, 2016).

Entre los factores responsables por el éxito de cualquier método de injerto, el principal es el contacto entre los tejidos meristemáticos del injerto y del portainjerto (HARTMANN et al., 2002). Según lo anterior, Mang'omban e Toit (2013) investigaron la influencia del largo de la superficie del corte diagonal del injerto y portainjerto en el método 'inglés' y registraron que el corte de largo $40 \mathrm{~mm}$ es el más recomendado para ese tipo de injerto, una vez que proporcionó $70 \%$ de sobrevivencia de las plantas injertadas de aguacate.

De acuerdo con Bettiol Neto y Pio (2016), a fin de evitar la deshidratación del injerto es necesario utilizar una bolsa plástica para proteger la región del injerto. En ese sentido, Jacomino et al. (2000), evaluando el efecto de diferentes materiales de protección durante el proceso de formación de plantas de aguacate 'Fortuna', concluyeron que los materiales Parafilm y film de policloruro de vinilo (PVC) fueron los más indicados en la protección del injerto del aguacate, resultando en una tasa de prendimiento del injerto de 80 y $53 \%$, respectivamente.

Otro factor importante que tiene influencia en el éxito del método de injerto es la época del año en el que el mismo es realizado, siendo indicados para las condiciones brasileñas los meses de noviembre y diciembre, cuando hay disponibilidad de varetas de las distintas variedades adecuadas para injertación (OLIVEIRA et al., 2008b). Para eso, dependiendo de la época de cosecha de los frutos de la planta madre del portainjerto, puede ser necesario almacenar las semillas, lo que es posible si son previamente tratadas con fungicida y acondicionadas en bolsas plásticas mantenidas en refrigeración o en recipientes que contengan aserrín humedecido (NEVES; MOREIRA, 1991).

Propagación vegetativa de portainjertos de aguacate - Por ser una especie de polinización cruzada y altamente heterocigótica, la multiplicación del aguacate por semilla origina una progenie altamente variable en relación a las características morfológicas y biológicas (OLIVEIRA et al., 2008a). La multiplicación utilizando métodos vegetativos garantiza para las nuevas plantas la expresión de características deseables de la planta madre, seleccionada por el aspecto nutricional, la tolerancia a enfermedades, menor porte, adaptación a condiciones edafoclimáticas específicas y por presentar buenas características de producción y calidad de fruto, además de permitir la producción de plántulas en larga escala a partir de la selección de determinado material genético (HARTMANN et al., 2002). 
Las primeras técnicas desarrolladas para la propagación vegetativa de plantas de aguacate datan de 1924, con la implementación de la propagación por estacas buscando la multiplicación de portainjertos con características superiores (SWINGLE; ROBINSON, 1924), siendo continuadas posteriormente por Eggers y Halma (1937) y por Haas (1937). Sin embargo, la propagación del aguacate por el método de estacas presenta algunas limitaciones por la síntesis excesiva de compuestos fenólicos, rápida oxidación y deshidratación de los tejidos, además de la formación de callos sin la emisión de raíces adventicias (PETRY et al., 2012; ESCOBEDO; ESCOBEDO, 2015; GLEESON et al., 2015).

Entre los principales factores que influencian el enraizamiento de estacas de aguacate están: (a) las características y edad de la planta madre; (b) tipos de estacas; (c) época de recolección de las estacas; (d) uso de reguladores vegetales; (e) tipo de sustrato; (f) intensidad de la luz; (g) calentamiento del medio de enraizamiento; (h) no remoción de las hojas de las estacas e (i) etiolamiento de las estacas (HARTMANN et al., 2002).

Los trabajos de investigación han indicado que, de manera general, el uso de estacas herbáceas en lugar de leñosas retiradas en la primavera, la reducción en $50 \%$ de la intensidad de la luz, la aplicación exógena de reguladores de crecimiento, el etiolamiento y el anillamiento (SILVEIRA et al., 2004) son técnicas útiles para mejorar el enraizamiento.

Mindêllo-Neto et al. (2006), evaluando diferentes concentraciones de la auxina sintética ácido indolbutírico (AIB) en estacas herbáceas de aguacate cv. 'Fuerte' (híbrido de las razas guatemalteca $\mathrm{x}$ mexicana), verificaron que la inmersión de las estacas por 5 segundos en solución de $500 \mathrm{mg} \cdot \mathrm{L}^{-1}$ de AIB promovió el enraizamiento de $47,5 \%$ de las estacas, mientras que las inmersas por 5 segundos en concentraciones de 2.000 y $4.000 \mathrm{mg} . \mathrm{L}^{-1}$ de AIB exhibieron un enraizamiento de 32,5 y $30,0 \%$, respectivamente. Además, el enraizamiento fue nulo cuando las estacas fueron inmersas en la solución AIB durante 24 horas, independientemente de la concentración del regulador utilizado. Ese estudio demostró que la concentración de la hormona sintética en valores superiores a lo necesario para el estímulo del enraizamiento ocasionó desequilibrio entre las hormonas promotoras e inhibidoras, y consecuentemente, el no enraizamiento de las estacas.

Cuando el enraizamiento por estacas es difícil, se puede usar el proceso de acodo subterráneo combinado con el etiolamiento de los ramos de aguacate, descrito inicialmente en África del Sur por Ernst y Holtzhausen (1978). El etiolamiento de los ramos (BIASI, 1996) promueve su enraizamiento porque aumenta la concentración de auxinas, disminuye la lignificación de los tejidos, aumenta el acúmulo de almidón en la región etiolada y disminuye el contenido de co-fatores negativos al enraizamiento (HARTMANN et al., 2002).

La técnica del etiolamiento fue descrita por primera vez por Frolich (1951) que obtuvo éxito en el enraizamiento de estacas fisiológicamente maduras de aguacate de la raza guatemalteca. Estudios posteriores llevaron al desarrollo de la técnica para la producción comercial de plántulas clonales de aguacate (FROLICH; PLATT, 1972) y variaciones de la misma ya fueron descritas por diversos autores desde entonces (BARRIENTOSPRIEGO et al., 1992; MOLL; WOOD, 1980), siendo actualmente utilizadas a nivel comercial en los Estados Unidos, Australia, Israel y África del Sur (ERNST et al., 2013) para la producción clonal de portainjertos de aguacate con características superiores.

Silveira et al. (2004) verificaron que el etiolamiento proporcionó el enraizamiento de $62,5 \%$ de las estacas de aguacate 'Ouro Verde' (híbrido de las razas guatemalteca y antillana), mientras que el cultivar Baronesa (raza antillana) no presentó ninguna estaca enraizada, indicando que el etiolamiento no es una práctica efectiva para todos los cultivares. El trabajo de Petry et al. (2012) relató que no solo el etiolamiento, sino también el anillamiento del tallo, se confirmaron como técnicas eficientes en la propagación del aguacate.

\section{Obtención de portainjertos clonales e injerto de la variedad}

Método de Frolich y Platt (1972)

El método de propagación de portainjertos clonales se inició con los investigadores Frolich y Platt (1972) de la Universidad de California, Riverside, Estados Unidos. Esta metodología innovadora para la obtención de portainjertos por métodos vegetativos revolucionó la forma de propagar el aguacate en todo el mundo. El uso comercial de esta técnica se hizo popular en la década de 1970 en California, cuando algunos viveros substituyeron los portainjertos de semillas por portainjertos clonales con características de tolerancia a patógenos (principalmente a Phytophthora cinnamomi), tolerancia a déficit hídrico y a suelos salinos, entre otras características (CASTRO; FASSIO, 2013a, b).

El método de Frolich y Platt (1972) consiste en producir una planta de aguacate por semilla y cuando esta alcanza el diámetro adecuado (Figura 1a), se realiza el injerto por púa terminal o hendidura simple del cultivar que se desea propagar como portainjerto (Figura 1b). Después de la unión completa del injerto (Figura 1c), se remueven los brotes del injerto (Figura 1d), y posteriormente las plantas son llevadas a una cámara oscura (Figura 1e) para que ocurra el etiolamiento de los brotes de las yemas del injerto. Cuando estos brotes alcanzan cerca de 8 a 10 $\mathrm{cm}$ de largo, se retiran las plantas de la cámara oscura (Figura 1f) y las mismas son transferidas a un ambiente iluminado. En este lugar, que debe ser semi-sombreado, se cubre todo el perímetro del tallo de las ramas etioladas con 
un cilindro de material plástico o metálico, conteniendo sustrato húmedo, a fin de mantener esa región protegida de la luz, dejando descubiertas apenas las extremidades apicales de las ramas, permitiendo que las hojas expuestas se desarrollen y recuperen la clorofila (Figura $1 \mathrm{~g}$ ). Cuando estas plántulas muestran un buen desarrollo (Figuras 1h, 1i), se retira el cilindro que cubría las ramas y con una tijera de podar se cortan las ramas etioladas que estarán listas para ser enraizadas como estacas (Figuras 1j, 1k). Entre seis y ocho semanas después las estacas estarán enraizadas (Figura 11) y listas para ser trasplantadas a bolsas plásticas de mayor capacidad y climatizadas. Las estacas enraizadas y establecidas, pueden ser injertadas con la variedad de interés comercial.
Este método también permite la realización del anillado para forzar la emisión de raíces en las ramas etioladas. En este caso, cuando las plántulas son retiradas de la cámara oscura, se hace un anillamiento en la base de la rama en todo el perímetro del tallo del brote etiolado. De la misma forma, se envuelve esta región del tallo del brote, con un cilindro de material plástico o metal rellenado con sustrato, así como ocurre en el proceso de propagación por acodos, de modo que se mantenga la región protegida de la luz y estimule el proceso del enraizamiento. En este caso, el enraizamiento ocurrirá en la región del anillado, siendo el resto del proceso idéntico al explicado anteriormente (FROLICH; PLATT, 1972).
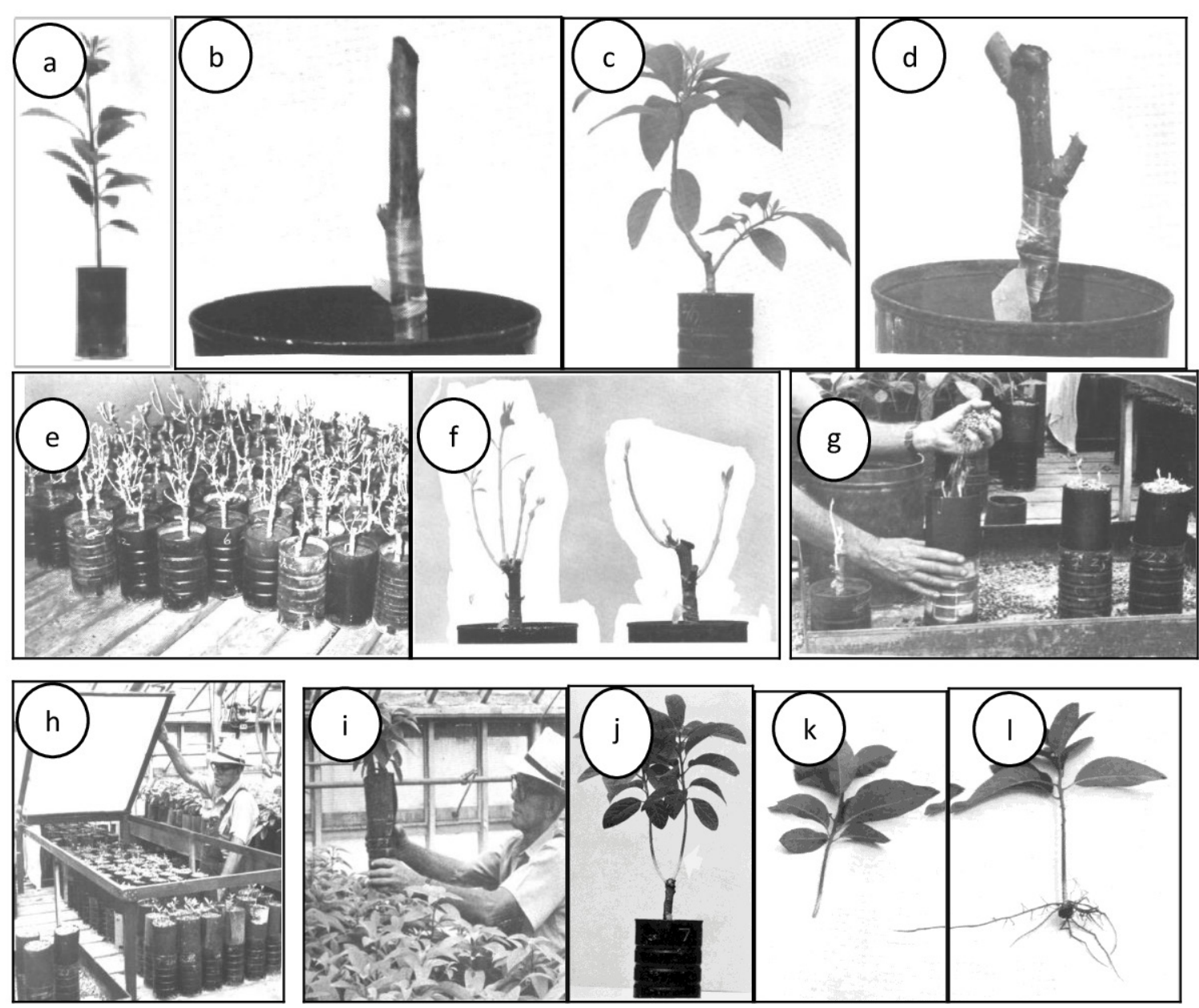

Figura 1. Técnica de Frolich y Platt para el enraizamiento de portainjertos clonales de aguacate (FROLICH; PLATT, 1972). Planta obtenida de semilla (a); Injerto por púa terminal o hendidura simple del portainjerto (b); Establecimiento del injerto (c); Reducción de los brotes (d); Plantas almacenadas en cámara oscura (e); Brotes etiolados (f); Recubrimiento de los brotes etiolados con cilindro rellenado de sustrato (g); Plantas en ambiente semi-sombreado (h); Plantas lista para reproducción por estacas (i); Plantas lista para reproducción por estacas después de la retirada del cilindro recubridor (j); Estaca retirada de la planta (k); Estaca enraizada (l). 
Método Brokaw

Una de las modificaciones de la técnica de Frolich y Platt (1972) corresponde al método desarrollado por el vivero 'Brokaw' localizado en el Condado de Ventura, California, Estados Unidos, y que actualmente es la técnica más utilizada para la producción de plántulas de aguacate en California, África del Sur (ERNST et al., 2013), Australia, España, Israel, Perú y Chile. Este método consiste en las siguientes etapas (Figura 2):

- Obtención de la semilla 'madre': La semilla 'madre' será fuente de nutrimentos para el desarrollo inicial del portainjerto. Para obtener una semilla libre de plagas y patógenos es necesario recolectarla directamente de la planta matriz, en el estado de madurez fisiológica del fruto, momento ideal para la germinación del embrión. Después de la extracción manual de las semillas de los frutos, estas deben ser lavadas con agua corriente de modo que se pueda remover totalmente la película que las envuelve. Posteriormente, son expuestas en un lugar sombreado por algunos días hasta que se sequen completamente, cuando entonces son llevadas a una mesa de pre-germinación, donde son raspadas en la parte basal, con el objetivo de anticipar la emisión de la radícula $\mathrm{y}$ posteriormente son desinfectadas con fungicidas. Se realiza la pre-germinación en bandejas o cajas plásticas conteniendo sustratos estériles y bien humedecidos. Después de 12 a 15 días, aproximadamente, se inicia la emisión de las radículas.

- Siembra: Primeramente, se prepara el recipiente que acondicionará las plantas. Se utiliza una bolsa plástica de 2 litros, la cual debe ser doblada externamente hasta la mitad de su extensión. La bolsa se rellena con sustrato hasta la mitad de su capacidad, posteriormente con las manos se abre una cavidad en el interior del sustrato, de modo a facilitar el acondicionamiento de la radícula en el momento de la siembra. Cuidadosamente, se introduce la semilla con la radícula en la cavidad del sustrato. Posteriormente, se recubre con sustrato el volumen restante del recipiente (Figura 2.1). Después de dos días aproximadamente, se observa el inicio de la brotación de la semilla 'madre'. En un período de 3 a 4 semanas, los brotes ya estarán con un espesor de $1 \mathrm{~cm}$ y aptos para recibir el injerto del cultivar del portainjerto deseado (Figura 2.2).

- Primer injerto (injerto del cultivar del portainjerto): Para la realización del primer injerto, se colectan cuidadosamente las ramas punteras (varetas) de la planta madre sana, cerciorándose que se encuentran libres de daños físicos. Se procede a su desinfección con hipoclorito de sodio y se almacenan en una caja de estereofón, con el propósito de mantenerlas en condiciones de baja temperatura y alta humidad relativa. Se realiza el injerto por el método de púa terminal o hendidura simple
(Figura 2.3). Trancurridos entre 15 a 30 días, se inician las brotaciones del injerto. Una vez que los brotes alcanzan aproximadamente $5 \mathrm{~cm}$ y los folíolos se encuentran abiertos, la planta estará en condiciones de ser llevada para la cámara de etiolamiento, que corresponde a un local sin luz (Figura 2.4). En su interior, la temperatura debe ser mantenida entre 25 a $35^{\circ} \mathrm{C}$ y la humedad relativa del aire de 60 a 70\%, siendo el riego de las plantas realizado según la necesidad. Se espera que ocurra el etiolamiento de los brotes, con su concomitante pérdida de coloración, y el estiramiento de estos hasta que alcanzan una altura de 30 a $40 \mathrm{~cm}$. Posteriormente, se selecciona el brote de mayor vigor (caso se presente más de un brote en la misma planta) y se retiran las plantas de la cámara de etiolamiento. Transcurridos 15 días, se raspa con una mini sierra, todo el perímetro de la región basal del brote y entonces se aplica una mezcla de ácido indolbutírico (AIB) y ácido naftaleno acético (ANA), para favorecer la emergencia de raíces adventicias del portainjerto clonal. Se deja secar por 20 minutos y posteriormente se coloca un anillo de material plástico o metal en la base del tallo del brote (Figura 2.5). Este anillo no debe quedar ni suelto ni muy apretado. Ese procedimiento se realiza para que después de aproximadamente un año, el anillo estrangule la planta 'madre'. Este paso, es la clave de este sistema de propagación, ya que si el anillo no fue colocado de forma correcta es posible que se abra y no interrumpa la conexión con el sistema radicular de la semilla 'madre'. Al finalizar la colocación del anillo, finalmente se desdobla la parte del recipiente que estaba doblada sobre si y se rellena con sustrato hasta su capacidad máxima (Figura 2.6). De este modo se mantiene la base del brote etiolada en la ausencia de luz, estimulando aún más la emergencia de las raíces adventicias del portainjerto clonal (Figura 2.7).

\section{- Segundo injerto (injerto de la copa del} cultivar): Primeramente, se colectan las ramas (varetas) de la variedad a ser propagada. Se realiza el injerto por el método de púa terminal o hendidura simple, sin embargo ahora, en una región más alta del brote del portainjerto clonal, cerca de 20 a $25 \mathrm{~cm}$ de la base, pues caso falle el injerto, es posible reinjertar nuevamente (Figura 2.8). Después de aproximadamente 4 a 5 semanas, se inician las brotaciones del nuevo injerto del cultivar comercial (Figura 2.9).

- Climatización: Se transportan las plantas para un local semi sombreado. Después de 20 a 30 días, las plantas son colocadas al aire libre y trasplantadas en un recipiente con capacidad de 12 litros para ser posteriormente plantadas en campo (Figura 2.10). 


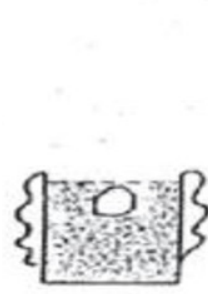

1

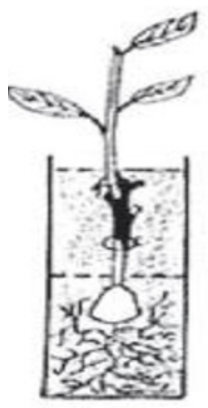

6
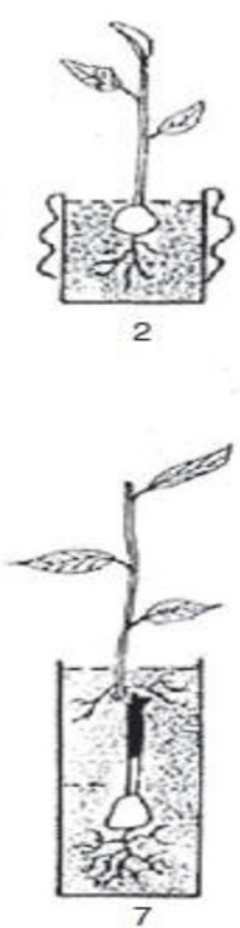
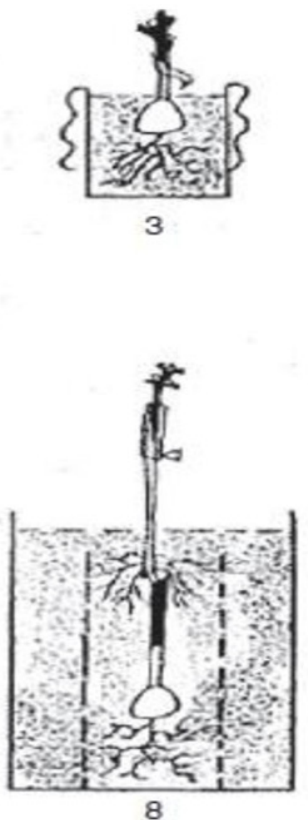

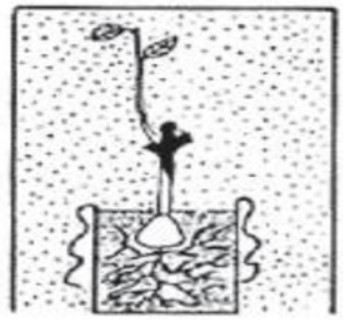

4

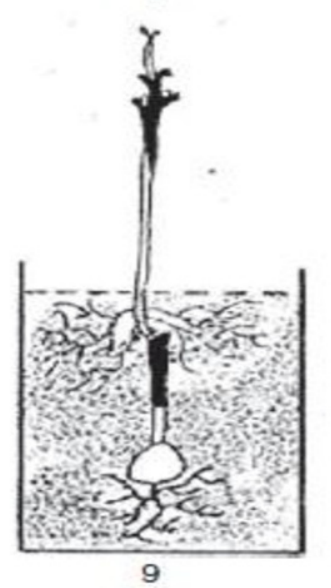

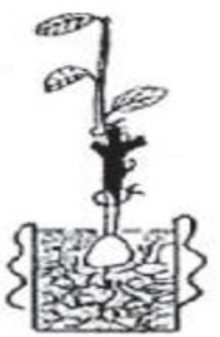

5

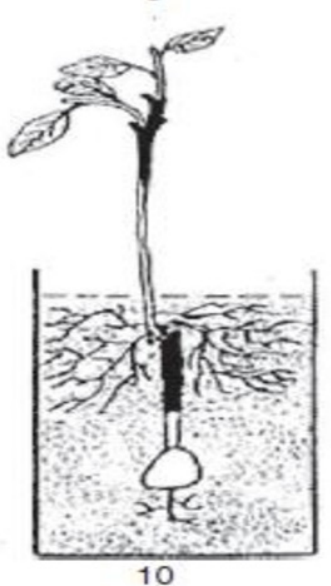

Figura 2. Técnica de Brokaw para enraizamiento de portainjertos clonales de aguacate (ERNST et al., 2013). Siembra de la semilla 'madre' (1); Planta lista para recibir el injerto (2); Injerto del cultivar portainjerto a ser aprovechado (3); Brote etiolado en cámara oscura (4); Anillamiento del brote etiolado (5); Recubrimiento de la base del brote etiolado (6); Emergencia de las raíces adventicias do broto etiolado (7); Injerto de la variedad a ser propagada (8); Brotaciones del nuevo injerto (9); Planta en recipiente, lista para trasplante en campo (10).

Método Allesbeste

Para reducir los costos de producción de portainjertos clonales, Ernst (1999) desenvolvió en el vivero 'Allesbeste' en África del Sur, la técnica de producción de micro clones a partir de una modificación del método 'Brokaw' (Figura 3). El método de micro clonaje consiste en la siembra de la semilla 'madre' (Figura 3.1) y cuando el brote alcanza grosor suficiente (Figura 3.2), es injertada de púa terminal con una vareta del cultivar del portainjerto a ser clonado (Figura 3.3). Después de esto, las varetas de portainjerto son rebajadas a 2 yemas. Cuando surgen las brotaciones de las yemas del portainjerto, se lleva la planta a la cámara de etiolamiento con buena ventilación y temperatura aproximada de $25^{\circ} \mathrm{C}$. Las brotaciones etioladas del portainjerto se desarrollarán $\mathrm{y}$, en este caso, se pueden seleccionar 2 brotes por planta (Figura 3.4). Cuando estos brotes alcanzan un largo de 20 a $30 \mathrm{~cm}$, se retira la planta de la cámara de etiolamiento. Se realiza una incisión en la base de cada brote etiolado y se aplica AIB en una concentración de $0,7 \%$. Se envuelve la base etiolada de cada brote con un mini contenedor de polietileno rellenado con sustrato estéril y un fertilizante de liberación lenta (Figura 3.5). Después de aproximadamente 8 semanas, los brotes ya estarán enraizados (Figura 3.6). Entonces, se injertan con varetas de la variedad comercial por el método de púa terminal o hendidura simple (Figura 3.7). Posteriormente, se almacena la plántula en un cuarto a $28^{\circ} \mathrm{C}$ y $75 \%$ de humedad relativa. Pasadas 4 a 6 semanas del segundo injerto, los micro clones estarán plenamente desarrollados (Figura 3.8) y cuando el injerto de la variedad comercial tenga aproximadamente $5 \mathrm{~cm}$ de largo, se cortan ambos brotes de la planta 'madre' en la región inmediatamente encima del primer injerto y abajo del mini-contenedor (Figura 3.9), siendo prontamente colocados en un recipiente con agua. Después de la separación, la plántula de la semilla 'madre' retorna para el cuarto de etiolamiento, donde se espera que ocurran nuevas brotaciones para proseguir con el proceso de microclonaje. Los micro clones son almacenados en invernaderos con alta humedad relativa $(85 \%)$ y mantenidos bajo sistema de fertirrigación, siendo generalmente vendidos directamente a los productores o para otros viveros $y$, caso no sean vendidos rápidamente, son trasplantados para bolsas plásticas para su posterior plantio en campo (Figura 3.11 e 3.12). El proceso completo de obtención de la planta desde la semilla 'madre' hasta los micro clones climatizados lleva cerca de 8 a 10 meses, más 4 a 6 meses adicionales hasta alcanzar el tamaño adecuado para su plantío definitivo en el campo (ERNST, 1999).

Esta es una de las ventajas de la técnica del vivero 'Allesbeste', pues se pueden producir varios clones a partir de una única semilla-madre (Figura 3.10). Otra ventaja de 
esta técnica es que en la separación de los micro-clones por escisión, ocurre la separación total de los sistemas radiculares de la semilla madre y del portainjerto clonal, lo que no siempre se garantiza con el método 'Brokaw', pues el anillo metálico puede no realizar la separación física de ambos sistemas radiculares por estrangulamiento. Otra ventaja del método 'Allesbeste' es que permite producir plántulas clonales adecuadas para la exportación, por ser pequeñas, leves y estar siempre en conformidad con los más altos estándares fitosanitarios internacionales (DE VILLIERS; ERNST, 2007).

Una modificación de la técnica del vivero 'Allesbeste' fue descrita por Reuben Hofshi (1996a, b) en Fallbrook, California, antes de la publicación oficial de Ernst (1999). En este método el portainjerto adquiere un buen enraizamiento y posee la ventaja de no destruir la planta 'madre', pudiendo esta ser reutilizada para la formación de nuevos portainjertos. Consecuentemente, menos semillas son necesarias para producir un grande número de clones, reduciendo los costos de la técnica. El proceso inicial es idéntico a los métodos anteriormente mencionados: la planta es injertada y etiolada. Cuando la planta es retirada de la cámara oscura, el brote etiolado recibe cuidadosamente incisiones con auxilio de una lámina en todo el perímetro del tallo, a una altura de aproximadamente $7 \mathrm{~cm}$ por encima de la región del injerto. Inmediatamente se aplica en el área de los cortes una solución de AIB a una concentración de $10 \mathrm{~g} \mathrm{~L}^{-1}$. Posteriormente, se insiere una estaca de bambú en el recipiente, sirviendo como un tutor al brote etiolado. Entonces, con una cinta adhesiva se fija un vaso plástico (240 mililitros) transparente, con la base libre alrededor del brote etiolado y en la región de la aplicación de la hormona de enraizamiento. En seguida, se rellena el vaso plástico con sustrato estéril y con una cinta adhesiva se fija al tutor de bambú (Figura 4a). Si el brote etiolado fuera suficientemente largo, un segundo vaso plástico puede ser colocado de la misma manera, cerca de $20 \mathrm{~cm}$ encima del primero. Alrededor de un mes después, dependiendo de las condiciones ambientales, ya será posible visualizar las raíces adventicias en las paredes del vaso transparente (Figura 4b). Cuando el brote alcanza un buen crecimiento aéreo, se injerta la copa de la variedad comercial y cuando este segundo injerto desarrolla brotes con cerca de 6 a 10 $\mathrm{cm}$ de largo, la nueva planta clonal es entonces separada de la semilla 'madre', trasplantada a un nuevo recipiente y mantenida en un lugar con temperatura y humedad relativa del aire controlados, hasta que esté en condiciones adecuadas para el plantío en local definitivo, mientras que la semilla 'madre' podrá ser sembrada nuevamente para producir un segundo portainjerto clonal (HOFSHI, 1996a, b).
El mayor beneficio de obtener una planta de aguacate sobre portainjerto clonal está en la superioridad del enraizamiento y desarrollo radicular (BEN-YA'ACOV; MICHELSON, 1995; DE VILLIERS; ERNST, 2007; DE VILLIERS; ERNST, 2015; FASSIO et al., 2016), con efecto positivo sobre el desempeño de la planta en el campo (DE VILLIERS; ERNST, 2007). Resultados diferentes fueron observados por Fassio et al. (2016) quienes, cuantificando los efectos de la técnica de propagación del portainjerto y del injerto de la variedad comercial sobre la arquitectura de las raíces del aguacate, verificaron que el injerto sobre portainjerto clonal o de semilla produjo plantas con arquitecturas semejantes de raíces. El estudio también reveló que el injerto tiene efecto significativo sobre el desarrollo de las raíces principales y laterales del portainjerto de aguacate. De esa forma, el injerto puede mejorar la eficiencia en la absorción de agua y nutrientes en ambos tipos de portainjertos, reduciendo así el tiempo de producción de las plantas en vivero.

\section{Micropropagación}

La micropropagación consiste en la aplicación de técnicas de cultivo de tejidos para la multiplicación de plantas a larga escala, utilizando pequeñas partes del vegetal (explantes) en condiciones asépticas, con ventajas en términos nutricionales, de sanidad y calidad de las plantas micro propagadas. También permite mantener los genes de interés, proporcionando mayor estabilidad genética y la obtención de materiales más tolerantes a enfermedades radiculares, como por ejemplo, la pudrición radicular causada por $P$. cinnamomi y a estreses ambientales, además de reducir el tiempo necesario para la obtención de las plantas (HARTMANN et al, 2002). A pesar de los aspectos positivos presentados, la micropropagación para el cultivo del aguacate puede no ser efectiva debido a la rápida oxidación y necrosis de los tejidos del explante (CASTRO et al., 1995). Sin embargo, tal técnica se presenta como una alternativa a la reducción de la variabilidad genética de plántulas provenientes de semillas (NHUT et al., 2008).

Por medio del cultivo de brotes y de la embriogénesis somática, es posible recuperar plantas de aguacate a partir de células y cultivo de tejidos. El cultivo de brotes es muy útil como método alternativo a la propagación vegetativa de materiales exclusivos, particularmente de nuevas selecciones de portainjerto. Por su parte, la embriogénesis somática es fundamental para la manipulación del genoma, utilizando la transformación genética y la inducción de mutaciones in vitro (PLIEGO-ALFARO et al., 2013). 


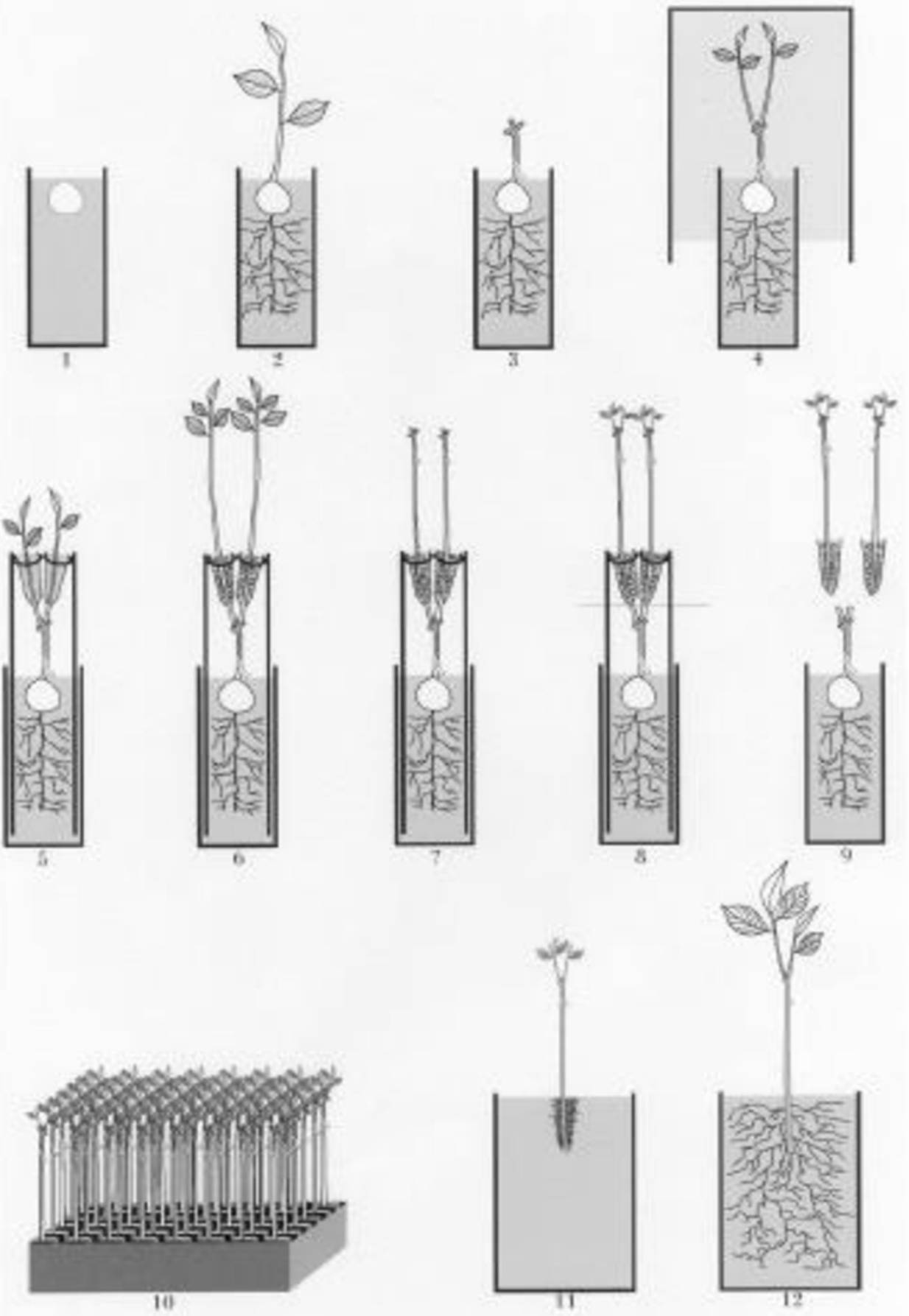

Figura 3. Técnica 'Allesbeste' de micro clonaje de portainjertos de aguacate adaptada de Brokaw (ERNST, 1999; ERNST et al., 2013). Siembra de la semilla 'madre' (1); Planta establecida para recibir el injerto (2); Injerto del cultivar portainjerto a ser aprovechado (3); Brotes etiolados (4); Brotes envueltos por mini contenedores (5); Enraizamiento de los brotes etiolados (6); Injerto de la variedad comercial (7); Micro clones desarrollados (8); Separación de los micro clones de la planta 'madre' (9); Micro clones listos para la comercialización (10); Micro clon trasplantado para bolsa plástica (11); Planta lista para el trasplante en campo (12). 


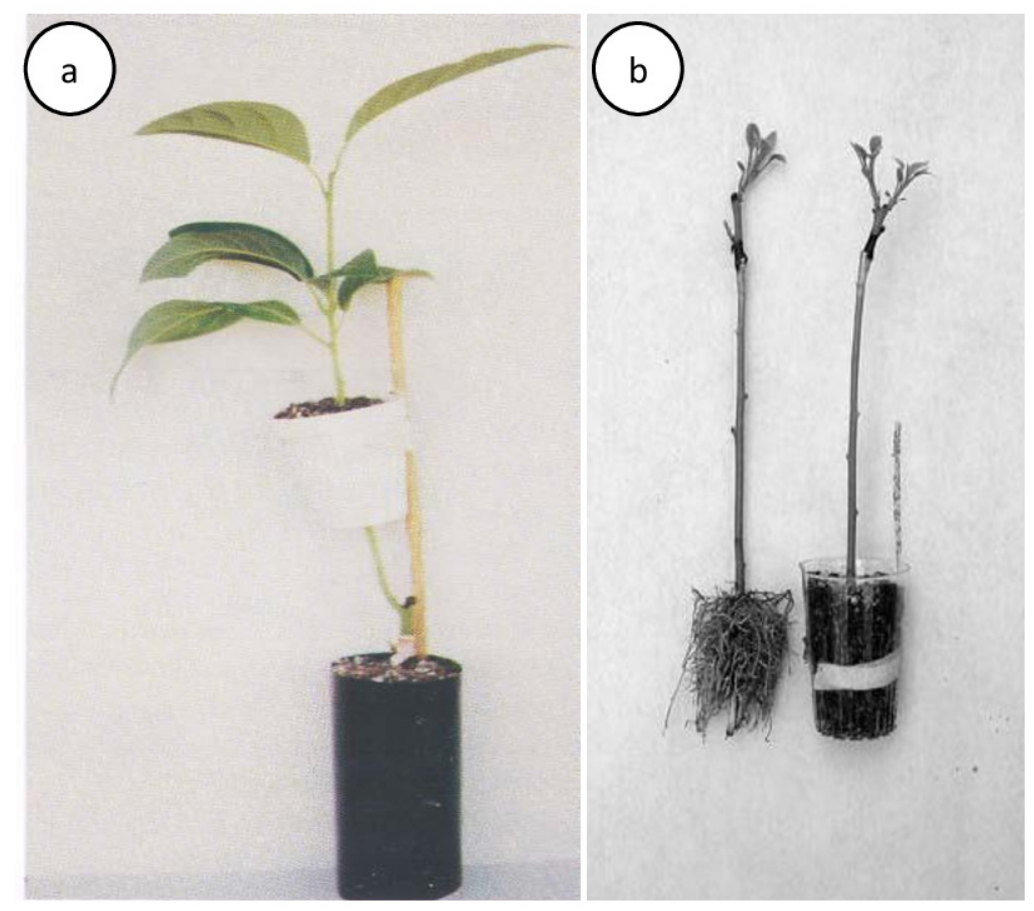

Figura 4. Clonaje del portainjerto de aguacate por el método de Hofshi adaptado de Brokaw (ERNST et al., 2013). Brote recubierto por vaso plástico rellenado con sustrato y tutorado por bambú (a); Raíces adventicias del brote etiolado (b).

Estudios relacionados a la micropropagación de aguacateros han sido conducidos por diversos autores a fin de determinar estrategias que faciliten la propagación in vitro, pues factores como el tipo y preparo del explante, las condiciones de la planta madre y el medio de cultivo, entre otras razones, pueden influenciar directamente en el éxito de la técnica (GEORGE et al., 2008). De esa forma, son necesarias estrategias que busquen facilitar la micropropagación, como la utilización de hormonas y otras sustancias promotoras del desarrollo vegetativo (NHUT et al., 2008), así como la determinación de la edad de la planta y de los órganos vegetales más apropiados para la colecta de explantes, tales como las brotaciones apicales (HARTY, 1985), los embriones cigóticos (RODRÍGUEZ et al., 1999; FUENTES et al., 2004) y los segmentos nodales (BIASI et al., 1994; BARCELÓ-MUÑOZ et al., 1999); además del tratamiento de explantes a partir del uso de desinfectantes (GEORGE et al., 2008).

Cortés-Rodríguez et al. (2011) colocaron yemas axilares obtenidas de aguacateros de la raza mexicana en medios de cultivo suplementados con diferentes concentraciones de benziladenina (BA) combinada con ácido indol-3-butírico (IBA), mientras que Zirari y Lionakis (1994) verificaron el efecto del tipo de explante, de la realización del etiolamiento y de la edad del material sobre la capacidad regenerativa de plantas in vitro de los cultivares Fuerte, Hass y Topa-Topa y encontraron como resultado una mayor capacidad de los brotes vegetativos en producir raíces, comparados con los segmentos nodales individuales, siendo el 'Topa-Topa' el cultivar con mayor número de brotaciones laterales, seguido de
'Fuerte' y 'Hass'. En relación al uso de medios de cultivo suplementados, Cortés-Rodríguez et al. (2011) obtuvieron el mejor porcentaje de inducción de brotaciones con las dosis de $0,5 \mathrm{mg} . \mathrm{L}^{-1}$ de BA y $0,1 \mathrm{mg} . \mathrm{L}^{-1}$ de IBA.

Aunque hayan diversas investigaciones en el ámbito de la micropropagación del aguacate, destacándose los trabajos conducidos en Australia (GLEESON et al., 2015) y España (PLIEGO-ALFARO et al., 2013), aún son necesarios esfuerzos para su mejoramiento. Sin embargo, en California, existe la comercialización de plantas injertadas de aguacate, siendo el portainjerto producido en condiciones de laboratorio (SPANN, 2015).

\section{Obtención de cultivares de aguacate através programas de mejoramiento}

La utilización de portainjertos clonales para aguacate otorga algunos beneficios para la variedad a ser injertada, ya sea como aumento o reducción del vigor, precocidad de producción, calidad de frutos y productividad (CASTRO; FASSIO, 2013a). Además de lo anterior, el empleo de materiales adecuados puede conferir mayor resistencia contra enfermedades y plagas, déficit hídrico y salinidad (WHILEY, 1992; CASTRO et al., 2009; ERNST et al., 2013). Se hace necesario también la selección de cultivares portainjertos más adaptados para las diferentes regiones edafoclimáticas (CASTRO; FASSIO, 2015), así como la selección de variedades compatibles (WHILEY et al., 2007). 
En función de las condiciones climáticas, de las características fisicoquímicas de los suelos y de las preferencias de gusto de los consumidores locales, cada país posee una gama de cultivares portainjerto y copa, así como las combinaciones más utilizadas (BEN-YA'ACOV, 1987). Mundialmente, las copas más utilizadas son los híbridos 'Hass' $(\mathrm{G} \times \mathrm{M})$, 'Lamb Hass' $(\mathrm{G} \times \mathrm{M})$, 'Fuerte' $(G \times M)$, 'Semil 34' $(G \times A)$ y 'Monroe' $(G \times A)$, aunque los cultivares Simmonds (A), Ettinger (M) y Reed (G), representantes de las razas puras, sean también plantados. El cultivar Hass domina el mercado mundial, siendo responsable por más de $90 \%$ del volumen de aguacates comercializados (CRANE et al., 2013).

En Brasil, los cultivares copa son híbridos de las razas antillana y guatemalteca $(\mathrm{A} \times \mathrm{G})$ obtenidas por selección natural en las regiones Sudeste y Sur de Brasil (DONADIO et al., 2010). Esos cultivares pueden presentar maduración precoz ('Geada'), de estación media ('Quintal' y 'Fortuna') o tardía ('Breda' y 'Margarida'). Existe también el cultivo de 'Hass' destinado para el mercado de exportación. Sin embargo, para los cultivares de portainjerto no hay la definición de un único material genético a ser utilizado.

El desarrollo y lanzamiento de nuevos cultivares copa y portainjerto a través de programas de mejoramiento genético ha ocurrido en diversos lugares como California, México, Israel, África del Sur y Australia, siendo cada programa dirigido a la obtención de materiales con las características necesarias para superar las limitantes de cada región productora, aunque la utilización de cultivares derivados de plantas seleccionadas a partir de semilla todavía predomina en todo el mundo (CRANE et al., 2013). Países como África del Sur y Australia poseen programas de mejoramiento dirigidos a la obtención de materiales resistentes a $P$. cinnamomi y que presenten mayor productividad, mientras que los programas israelitas han orientado sus investigaciones a la obtención de mejores productividades a partir de interacciones copa/portainjerto y de la adaptación a ambientes edafoclimáticos estresantes (BEN-YA'ACOV; MICHELSON, 1995; CRANE et al., 2013).

Esos programas de mejoramiento han tenido como principal objetivo la obtención de cultivares de portainjertos de aguacate con características superiores. Inicialmente, las primeras selecciones de portainjertos fueron orientadas a la obtención de materiales tolerantes a condiciones climáticas adversas, como el frio. En California fueron seleccionados portainjertos de la raza mexicana tolerantes al frio, como el cv. 'Topa-Topa', mientras que en África del Sur fueron seleccionados portainjertos tolerantes al frio, pero de la raza guatemalteca (cv. 'Edranol'). Sin embargo, todos esos portainjertos tolerantes al frio resultaron muy susceptibles a patógenos del suelo. A partir de la década de ' 70 , los principales programas de mejoramiento de aguacate en el mundo se orientaron a la obtención de portainjertos tolerantes a la pudrición radicular (BERGH et al., 1976; KELLAM; COFFEY, 1985; KÖHNE, 1992). Otros objetivos utilizados para la selección de portainjertos son la tolerancia a condiciones salinas y calcáreas del suelo (KADMAN; BEN-YA'ACOV, 1976; KADMAN, 1985) y a la baja aireación del suelo, asi como la reducción del vigor de la copa.

Los principales objetivos de la selección de portainjertos en Australia han sido también la tolerancia a la pudrición radicular y su efecto en la productividad y calidad poscosecha de los frutos. En relación a la resistencia de los materiales genéticos a las enfermedades, estudios conducidos en Australia por Smith et al. (2011) demostraron la superioridad de las selecciones 'SHSR02' y 'SHSR-04', obtenidas por multiplicación seminal y clonal respectivamente, y del portainjerto clonal 'Dusa', cuando injertados con 'Hass', en la tolerancia a P. cinnamomi al compararlos con los portainjertos 'Reed' (seminal), 'Velvick' (seminal o clonal) y 'A10' (seminal). Actualmente en el programa de mejoramiento australiano, están siendo evaluadas en distintas regiones del país algunas selecciones de portainjertos obtenidas a partir de plantas escape.

En África del Sur la empresa Westfalia Technological Services conduce desde 1993 un importante programa de selección y evaluación de portainjertos, con bloques de plantas matrices de germoplasma mexicano para el cruzamiento y generación de portainjertos tolerantes a pudrición radicular, que reduzcan el tamaño de la planta y que mejoren la producción (ROE et al., 1995; KREMERKÖHNE et al., 2002; VAN ROOYEN, 2011). En este programa también son evaluados materiales importados de otros países. En 2001 fue lanzado comercialmente el portainjerto 'Merensky 2' o 'Dusa', el cual es muy utilizado actualmente en plantaciones comerciales en Estados Unidos. Este portainjerto superó al portainjerto cv. 'Duke 7' en la tolerancia a la pudrición de raíces, vigor de planta y productividad para el cv. 'Hass', con buen desempeño en suelos salinos y pesados.

En México, la Fundación Salvador Sánchez-Colín y la Universidad Autónoma de Chapingo han trabajado en la selección y evaluación de germoplasma nativo de aguacate, concentrando los esfuerzos en la búsqueda de portainjertos tolerantes a Phytophthora y que brinden menor vigor a las copas (BARRIENTOS-PRIEGO et al., 1992), como el portainjerto 'Colin V-33', obtenido de una planta de semilla del cv. 'Fuerte' y que confiere efecto enanizante a la copa de 'Hass'.

Otro importante programa de mejoramiento de portainjertos fue desarrollado en el Volcani Center de Israel por Abraham Ben-Ya'acov y colaboradores, entre 1968 y 2001. El énfasis de ese programa fue la selección de portainjertos de semillas tolerantes a factores limitantes del suelo, como salinidad, altos niveles de carbonatos y suelos 
arcillosos, pero también resultaron en buena producción en el cultivar copa injertado. Entre los principales portainjertos de semillas seleccionados están los cultivares de las series 'Degania', 'Ashdoth', 'Tzriffin' y 'Nachlat'. En 1995 fueron liberados 20 cultivares de portainjertos de la serie VC, siendo los más importantes el 'VC 26', 'VC 51'y 'VC 40' (BEN-YA'ACOV; MICHELSON, 1995).

En los Estados Unidos, la Universidad de California de Riverside (UCR) ha liderado mundialmente la selección de portainjertos tolerantes a la pudrición radicular $(P$. cinnamomi). El programa de mejoramiento convencional de la UCR seleccionó portainjertos oriundos de semillas de la raza mexicana con tolerancia a $P$. cinnamomi, que a partir de 1977 comenzaron a ser propagados comercialmente por la técnica de clonaje de Frolich modificada por Brokaw. El portainjerto clonal de mayor éxito de este programa es el 'Duke 7', muy utilizado en los EUA y en África del Sur. De este programa se han originado otros cultivares de portainjertos mundialmente conocidos, como 'Thomas', 'Barr Duke', 'D9', 'Spencer', 'Toro Canyon' (BEN-YA'ACOV; MICHELSON, 1995), y más recientemente, los cultivares 'Stedom', 'Uzi' y 'Zentmyer' (MENGE et al., 2012), los cuales también demostraron buenas características agronómicas, cuando fueron injertados con la copa de 'Hass'.

En relación a la influencia en la alternancia en la producción (“on/off"), estudios conducidos por Mickelbart et al. (2007) demostraron que después de 10 años de investigaciones realizadas en la región de Irvine, California, todos los portainjertos evaluados ('Borchard', 'D9', 'Duke 7', 'G1033', 'G755A', 'G755B', 'G755C', 'Thomas', 'Topa Topa', 'Toro Canyon') en combinación con la copa 'Hass', presentaron un comportamiento padrón de alternancia productiva. Sin embargo, los diferentes porta-injertos influenciaron de manera distinta la intensidad de la bianualidad, tal y como fue observado en árboles injertados sobre 'Topa Topa' y 'Toro Canyon', en los cuales la alternancia de producción fue mayor al compararla con la de plantas injertadas sobre 'G755'. En estudios posteriores con los portainjertos 'Thomas', 'Topa Topa', 'Duke 7' y 'D9', Mickelbart et al. (2012) también observaron la ocurrencia de alternancia productiva, a pesar de no registrar diferencias entre los portainjertos en cuanto a la intensidad de esta variable.

Bórquez-Lillo et al. (2014) reportaron que el portainjerto clonal 'Duke 7' influenció el vigor y la precocidad de la floración en la copa de 'Hass' en relación al portainjerto oriundo de semillas. En un pomar adulto, localizado en África del Sur, De Villiers y Ernst (2015) registraron que el cultivar Hass sobre el portainjerto clonal 'Duke 7' presentó una producción de $67 \mathrm{~kg} /$ planta, mientras que en las plantas sobre 'Duke 7' obtenido a partir de semillas esa producción fue de $35 \mathrm{Kg}$ /planta, en el promedio de seis años de evaluaciones. A pesar de las diferencias entre los cultivares desarrollados por los distintos programas de mejoramiento, es válido resaltar que nuevos cultivares portainjertos fueron introducidos y evaluados en el mercado mundial (Cuadro 1).

En Brasil, todavía existen pocos cultivares de portainjertos disponibles para fines de propagación comercial, siendo representados principalmente por aquellos que presentan tolerancia al desarrollo de Phytophthora cinnamomi como el 'Duke 7' y el 'Toro Canyon', ambos desarrollados por el programa de mejoramiento de California (CRANE et al., 2013). 
Tabela 1. Principales cultivares de portainjertos para aguacate.

\begin{tabular}{|c|c|c|c|c|}
\hline Cultivar & $\begin{array}{l}\text { Programa de } \\
\text { Mejoramiento }\end{array}$ & Raza* & Resistencia/Tolerancia/Característica & Obtención \\
\hline 'Ashdot' & Israel & A & Salinidad & Semilla \\
\hline 'Barr Duke' & California & M & P. cinnamomi y frío & Clonal \\
\hline 'Borchard' & California & M & $\begin{array}{l}\text { P. citrícola (susceptible a P. cinnamomi) y } \\
\text { salinidad }\end{array}$ & Clonal \\
\hline 'Colin V-33' & México & M & $\begin{array}{l}\text { Confiere menor porte a las copas } \\
\quad \text { (utilizado con interinjerto) }\end{array}$ & Semilla \\
\hline 'Degania' 112 y 115 & Israel & $\mathrm{A}$ & Confiere menor porte a las copas & Semilla \\
\hline 'Degania 117 ' & & & Salinidad & Semilla \\
\hline 'Duke 7' & California & M & P. cinnamomi & Clonal \\
\hline 'Dusa' ('Merensky II') & África del Sur & GxM & P. cinnamomi & Clonal \\
\hline 'Latas’ ('Merensky I’) & África del Sur & M & Suelo encharcado/ P. cinnamomi & Clonal \\
\hline 'Mexicola' & California & M & Frío & Semilla \\
\hline 'Maoz' ('VC 43’) & Israel & A & $\begin{array}{c}\text { Suelos calcáreos, salinidad, confiere menor } \\
\text { vigor }\end{array}$ & Semilla \\
\hline 'Steddom' & California & M & P. cinnamomi y confiere menor vigor & Semilla \\
\hline 'Toro Canyon' & California & M & P. cinnamomi y $P$. citrícola & Clonal/Clonal \\
\hline 'Uzi' & California & M & P. cinnamomi & Clonal \\
\hline 'Velvick' & Australia & $\mathrm{AxG}$ & P. cinnamomi, Antracnosis en el fruto & Semilla/Clonal \\
\hline 'Zentmyer' & California & M & P. cinnamomi & Clonal \\
\hline ‘Zutano’ & California & $\mathrm{MxG}$ & Salinidad y frío & Semilla/Clonal \\
\hline
\end{tabular}

*A: antillana; M: mexicana; G: guatemalteca.(Adaptado de Crane et al., 2013).

Oliveira et al. (2008a) hicieron experimentos con 'Duke 7' a fin de evaluar la viabilidad de la propagación clonal de este portainjerto como opción para el injerto de las variedades tradicionalmente cultivadas en las condiciones brasileñas, no obteniendo resultados satisfactorios.
Otro cultivar portainjerto introducido recientemente en Brasil para fines de investigación en campo es el cv. 'Dusa', el cual, en la región de Bauru/SP, posibilitó mayor productividad, masa promedio y calibre de frutos en aguacates 'Hass' en comparación a portainjertos oriundos de semillas (MORAES, 2014). 
Los avances relacionados a la obtención de nuevos portainjertos son fundamentales, considerando que los clones 'Dusa', obtenido por la empresa sudafricana Westfalia Technological Services, y 'Duke 7', del programa de mejoramiento californiano, han proporcionado tolerancia adecuada a . cinnamomi, mayor productividad y calidad de los frutos; así como tolerancia a estreses edafoclimáticos (CRANE et al., 2013).

Según Ernst et al. (2013), la producción de aguacates será cada vez más dependiente de portainjertos clonales, siendo creciente la demanda por cultivares que presentan tolerancia a las condiciones de cada región productora (salinidad, alcalinidad, baja aireación, ocurrencia de enfermedades), tiene una relación costo/ beneficio aceptable y que proporcionan considerable lucro por unidad de área cultivada. El alcance de tal situación será posible solamente mediante la inversión constante en investigaciones, el reconocimiento de los esfuerzos de los grandes centros de estudio y la aceptación de los productores a la introducción de los nuevos materiales desarrollados.

El lanzamiento de diversas selecciones de variedades 'tipo Hass' en los últimos 10 a 20 años permitió la extensión del período de cosecha y la obtención de frutos de mejor calidad, con buena aceptación por los consumidores. Frente a la disponibilidad de esas variedades en el mercado externo y a la variabilidad climática brasileña, se vuelve imprescindible la introducción inmediata de nuevos materiales genéticos de aguacates tropicales y subtropicales en los huertos de Brasil. En el Cuadro 2 se presentan algunos cultivares con características interesantes que podrían ser utilizados en las condiciones edafoclimáticas brasileñas, con predominio de selecciones con características semejantes al 'Hass'. Sin embargo, para confirmar el potencial de estas variedades es necesario llevar a cabo experimentos con el objetivo de verificar la adaptación de estos genotipos a las condiciones locales.

Tabela 2 - Cultivares copa de aguacates con potencial para introducción en Brasil.

\begin{tabular}{ccccccc}
\hline Cultivar & $\begin{array}{c}\text { Programa de } \\
\text { Mejoramiento }\end{array}$ & $\begin{array}{c}\text { Grupo floral Época de } \\
\text { /(Raza) }\end{array}$ & $\begin{array}{c}\text { Masa } \\
\text { cosecha* }\end{array}$ & $\begin{array}{c}\text { Color de los } \\
\text { los frutos }(\mathrm{g})\end{array}$ & $\begin{array}{c}\text { frutos para } \\
\text { consumo }\end{array}$ & Formato del árbol \\
\hline 'Carmen-Hass' & México & $\mathrm{A} /(\mathrm{GxM})$ & $\mathrm{I} / \mathrm{P}$ & $200-285$ & $\mathrm{R}$ & Semi-vertical y arredondeado \\
'Maluma-Hass' & África del Sur & $\mathrm{A} /(\mathrm{GxM})$ & $\mathrm{P}$ & $150-400$ & $\mathrm{R} / \mathrm{P}$ & Vertical y esbelto \\
'Lamb Hass' & California & $\mathrm{A} /(\mathrm{GxM})$ & $\mathrm{P}$ & $235-405$ & $\mathrm{R} / \mathrm{P}$ & Vertical \\
'Gem' & California & $\mathrm{A} /(\mathrm{GxM})$ & $\mathrm{V}$ & 235 & $\mathrm{P}$ & Vertical y compacto \\
'Reed' & California & $\mathrm{A} / \mathrm{G}$ & $\mathrm{V}$ & $270-680$ & $\mathrm{~V}$ & Vertical y esbelto \\
'Shepard' & California & $\mathrm{B} / \mathrm{M}$ & $\mathrm{O}$ & $155-285$ & $\mathrm{~V}$ & Semi-enano y compacto \\
'Simmonds' & Florida & $\mathrm{A} / \mathrm{A}$ & $\mathrm{V}$ & $453-963$ & $\mathrm{~V}$ & Vertical \\
'Nesbitt' & Florida & $\mathrm{A} /(\mathrm{GxA})$ & $\mathrm{V}$ & $397-737$ & $\mathrm{~V}$ & Semi-horizontal \\
'Carla' & $\begin{array}{c}\text { República } \\
\text { Dominicana }\end{array}$ & $\mathrm{B} /(\mathrm{GxA})$ & $\mathrm{P}$ & $425-1243$ & $\mathrm{~V}$ & Semi-horizontal \\
'Semil 34' & Puerto Rico & $\mathrm{A} /(\mathrm{GxA})$ & $\mathrm{O} / \mathrm{I}$ & $396-700$ & $\mathrm{~V}$ & Obovado \\
\hline
\end{tabular}

" O: otoño; I: invierno; P: primavera; V: verano. " Color de la cáscara de los frutos: R: morado; P: negro; V: verde. (Adaptado de Crane et al., 2013).

\section{Conclusion}

Aún es necesario el desarrollo de estrategias comerciales que permitan la producción masiva de portainjertos clonales para satisfacer la demanda de plantas con calidad superior a partir de técnicas confiables realizadas por parte de los viveristas y que se muestren accesibles para productores de pequeño a grande porte (ERNST et al., 2013).
La demanda por plantas de calidad que presenten las mejores combinaciones copa/portainjerto para cada condición edafoclimática específica, así como la definición de manejos en función de las características de estas combinaciones es elevada (CASTRO, información personal $\left.^{1}\right)$. 
Aunado a eso, se busca la obtención de cultivares más productivos, con características agronómicas superiores, principalmente con relación a la calidad de los frutos (CRANE et al., 2013). Se cree que tales soluciones ocurrirán por la realización de investigaciones en el área de propagación de aguacate (CASTRO, información personal).

\section{Referencias}

ANDRADE-HOYOS, P.; ESPÍNDOLA BARQUERA, M.C.; DE LEÓN, C.; ROSALES, D.A.; JIMÉNEZ, A.L.; GAYOSSO, E.M. Totipotencialidad en plántulas de aguacate y la resistencia a Phytophthora cinnamomi. In: CONGRESO MUNDIAL DE LA PALTA, 8., 2015. Lima. Actas... p.147-153.

BARCELÓ-MUÑOZ, A.; ENCINA, C.L.; SIMÓNPÉREZ, E.; PLIEGO-ALFARO, F. Micropropagation of adult avocado. Plant Cell, Tissue and Organ Culture, Netherland, v.58, p.11-17, 1999.

BARRIENTOS-PRIEGO, A.; SANCHEZ-COLÍN, S.; LÓPEZ-JIMENEZ, A. Selection of avocado dwarfing rootstocks. In: WORLD AVOCADO CONGRESS, 2., 1992, Riverside, California. Proceedings... Riverside: California Avocado Society, 1992. p.515-520.

BEDENDO, I.P. Podridões de raiz e colo. In: AMORIN, L.; REZENDE, J.A.M.; BERGAMIN-FILHO, A. (Ed.). Manual de fitopatologia. Piracicaba: Agronômica Ceres, 2011. p. 443-449.

BEN-YA'ACOV, A. Avocado rootstock-scion relationships. South African Avocado Growers'Association Yearbook, Pretoria, v.10, p.30-32, 1987.

BEN-YA'ACOV, A.; MICHELSON, E. Avocado rootstocks. In: JANICK, J. (Ed.). Horticultural reviews. New York: John Wiley, 1995. v.17, p.381-429.

BERGH, B.O.; ZENTMYER, G.A.; WHITSELL, R.H.; BOSWELL, S.B.; STOREY, W. B. Avocado rootstock breeding, especially in relation to Phytophthora. Acta Horticulturae, The Hague, v.57, p.237-240, 1976.

BETTIOL-NETO, J.E.; PIO, R. Propagação de mudas de abacate. Campo \& Negócios, Uberlândia, v.8, n.130, p.71, 2016.

BIASI, L.A. Emprego do estiolamento na propagação de plantas. Ciência Rural, Santa Maria, v.26, n.2, p.309314, 1996.
La introducción de nuevos cultivares de copas y portainjertos de aguacates en Brasil y su evaluación en las condiciones locales, permitirá ampliar las plantaciones comerciales en regiones con restricciones de suelo o clima o con problemas fitosanitarios, así como reducir la desuniformidad de los pomares y obtener combinaciones mejor adaptadas a las condiciones locales.

BIASI, L.A.; KOLLER, O.C.; KÃMPF, A.N. Micropropagação do abacateiro 'Ouro Verde' a partir de segmentos nodais. Pesquisa Agropecuária Brasileira, Brasília, DF,v.29, n.7, p.1051-1058, 1994.

BÓRQUEZ-LILlo, C.; CASTRO, M.; FICHET, T.; CAUTÍN, R. Combined effect of rootstocks and uniconazol-p application via irrigation on the canopy of 'Hass' avocado trees. Revista Chapingo Serie Horticultura, Chapingo, v.21, n.3, p.243-255, 2014.

CASTRO, M.; CAUTÍN, R.; FASSIO, C.; DARROUY, $\mathrm{N}$. Introduction, selections and propagation program for avocado rootstocks and cultivars in Chile. In: WORLD AVOCADO CONGRESS, 5., 2003. Málaga. Proceedings... p.120-121.

CASTRO, M.; FASSIO, C. Innovación, desarrolho y transferencia de tecnologia de plantines clonales de palto em Chile. In: CONGRESO MUNDIAL DE LA PALTA, 8., 2015. Lima. Actas... p.34-36.

CASTRO, M.; FASSIO, C.; DARROUY, N.Evaluación agronómica y propagación de nuevos portainjertos y variedades de palto en distintas zonas agroclimáticas de Chile. In: WORLD AVOCADO CONGRESS, 6., 2007, Viña Del Mar. Proceedings... p.1-9.

CASTRO, M.; OYANEDEL, E.; CAUTÍN, R. In vitro shoot proliferation in avocado (Persea americana Mill.) induced by CPPU. In: WORLD AVOCADO CONGRESS, 3., 1995. Tel-Aviv. Proceedings... p.223-226.

CASTRO, M.V.; FASSIO, C.O. Evaluación agronómica de nuevos portainjertos de palto en distintas zonas agroclimáticas de Chile. Valparaíso: Pontificia Universidad Católica de Valparaíso, 2013b. 23p. (Manual Técnico, 2).

CASTRO, M.V.; FASSIO, C.O. Propagación clonal de paltos. Chile: Pontificia Universidad Católica de Valparaiso, 2013a. 23p. (Manual Técnico, 1).

CASTRO, M.V.; ITURRIETA, R.E.; FASSIO, C.O. Rootstock effect on the tolerance of avocado plants cv.Hass to $\mathrm{NaCl}$ stress. Chilean Journal of Agricultural Research, Chillán, v.69, n.3, p.316-324, 2009. 
CORTÉS-RODRÍGUEZ, M.A.; LÓPEZ-GÓMEZ, R.; MARTÍNEZ-PACHECO, M. M.; SUÁREZRODRÍGUEZ, L.M.; HERNÁNDEZ-GARCÍA, A.; SALGADO-GARCIGLIA, R.; VIDALES FERNÁNDEZ, I.; ÁNGEL PALOMARES, M.E. In vitro propagation of mexican race avocado (Persea americana Mill. var. drymifolia). Acta Horticulturae, The Hague, v.923, p.47-52, 2011.

CRANE, J.H.; DOUHAN, G.; FABER, B.A.; ARPAIA, M.L.; BENDER, G.S.; BALERDI, C.F. ; BARRIENTOSPRIEGO, A.F. Cultivars and Rootstocks. In: SCHAFFER, B.A.; WOLSTENHOLME, BN.; WHILEY, A.W. The avocado, botany, production and uses. $2^{\text {nd }} e d$. Homestead: CABI, 2013. cap.8, p.200-233.

DE VILLIERS, A.; ERNST, A.A. Avocado rootstock research: principles and practises. In: WORLD AVOCADO CONGRESS, 8., 2015. Lima. Proceedings. p.40-45.

DE VILLIERS, A.; ERNST, A.A. Practical value of the Allesbeste micro cloning technique. In: WORLD AVOCADO CONGRESS, 6., 2007. Viña del Mar. Proceedings... p.12-16.

DONADIO, L.C.; FERRARI, L.; CANTUARIASAVILÉS, T. Abacate. In: DONADIO, L.C. (Ed.). História da fruticultura paulista. Jaboticabal: Sociedade Brasileira de Fruticultura, 2010. p.33-63.

EGGERS, E.; HALMA, F. Rooting avocado cuttings. California Avocado Society Yearbook, Los Angeles, v.22, p.121-125, 1937.

ERNST, A. A.; HOLTZHAUSEN, L. C. New promising techniques for rooting difficult-to-root avocado (Persea americana Mill.) cuttings. Citrus and Subtropical Fruit Journal, Johannesburg, v.532, p.6-10, 1978 .

ERNST, A.A. Micro cloning: a multiple cloning technique for avocados using micro containers. Revista Chapingo, Serie Horticultura, Chapingo, v.5, p.217-220, 1999.

ERNST, A.A.; WHILEY, A.W.; BENDER, G.S. Propagation. In: SCHAFFER, B. A.; WOLSTENHOLME, B.N.; WHILEY, A.W. The avocado: botany, production and uses. $2^{\text {nd }}$ ed. Homestead: CABI, 2013. cap.9, p.234267.
ESCOBEDO, V.; ESCOBEDO, J. Propagación clonal de palto 'Duke' (Persea americana Mill.) utilizando esquejes com callos y raíces preformadas em su base estiolada y cámaras húmedas individuales. In: CONGRESO MUNDiAL DE LA PALTA, 8., 2015. Lima, Peru. Proceedings... p .66-69.

FASSIO, C.; CAUTÍN, R.; PÉREZ-DONOSO, A.; BONOMELLI, C.; CASTRO, M. Propagation techniques and grafting modify the morphological traits of roots and biomass allocation in avocado trees. Hort Technology, Virginia, v.26, n.1, p.63-69, 2016.

FROLICH, E.F. Rooting Guatemalan avocado cuttings. California Avocado Society Yearbook, New York, v.36, p.136-138, 1951.

FROLICH, E.F.; PLATT, R.G. Use of the etiolation technique in rooting avocado cuttings. California Avocado Society Yearbook, New York v.55, p.97-109, 1971-72.

FUENTES, J.L.; RODRÍGUEZ, N.N.; SANTIAGO, L.; VALDÉS, Y.; RAMÍREZ, I. M.; RODRÍGUEZ, J.A. Zygotic embryo culture in avocado (Persea americana Mill). Cultivos Tropicales, La Habana, v.25, n.3, p.7376, 2004.

GEORGE, E.F.; HALL, M.A.; KLERK, G.J. Plant tissue culture procedure - background. Plant propagation by tissue culture. $3^{\text {rd }}$ ed. Dordrecht: Springer Netherlands, 2008. p.1-28.

GLEESON, M.; HAYWARD, A.; BEVERIDGE, C.; CARROLL, B.; MITTER, N. Micro-Rna regulation of avocado adventious rooting for clonal rootstock propagation. In: CONGRESO MUNDIAL DE LA PALTA, 8., 2015 Lima, Perú. Actas... p.70-74.

HAAS, A. Propagation of the 'Fuerte' avocado by means of leafy-twig cuttings. California Avocado Society Yearbook, Santa Ana, v.22, p.126-130, 1937.

HARTMANN, H.T.; KESTER, D.E.; DAVIES JUNIOR, F.T.; GENEVE, R.L. Plant propagation: principles and practices. $7^{\text {th }}$ ed. New Jersey: Prentice Hall, 2002. 880p.

HARTY, P.A. Propagation of avocados by tissue culture: development of a culture medium for multiplication of shoots. South African Avocado Growers' Association Yearbook, Tzaneen, v.8, p.70-71, 1985. 
HOFSHI, R. Clone your own avocado at home. Subtropical Fruit News, Riverside, v.4, n.2, p.4-6, 1996a.

HOFSHI, R. Experiments with cloning avocado rootstocks. California Avocado Society Yearbook, Santa Ana, v.80, p.103-108, 1996 b.

JACOMINO, AP.; MINAMI, K.; KLUGE, RA.; KISHINO, A.Y. Métodos de proteção de enxertos na produção de mudas de mangueira, abacateiro e nogueiramacadâmia. Pesquisa Agropecuária Brasileira, Brasília, v.35, n.10, p.1985-1990, 2000.

KADMAN, A. Selection of avocado and mango rootstocks for calcareous soils. Acta Horticulturae, The Hague, v.158, p.63-67, 1985.

KADMAN, A.; BEN-YA'ACOV, A. Selection of avocado rootstocks for saline conditions. Acta Horticulturae, The Hague, v.57, p.189-197, 1976.

KELLAM, M.K.; COFFEY, M.D. Quantitative comparison of the resistance to Phytophthora root rot in three avocado rootstocks. Phytopathology, Palo Alto, v.75, p.230-234, 1985.

KÖHNE, J.S. Field evaluation of 'Hass' avocado grown on 'Duke 7', 'G6' and 'G755C' rootstocks. In: WORLD AVOCADO CONGRESS, 2., 1992. Riverside. Proceedings... v.1, p.301-303.

KREMER-KOHNE, S.; DUVENHAGE, J.A.; MAILULA, S.M. Breeding and field testing of new avocado rootstocks for increased Hass yields and resistance to root rot progress report. South African Avocado Growers Association Yearbook, Tzaneen, v.25, p.17-19, 2002.

KROON, L.P.N.M.; BROUWER, H.; COCK, A.W.A.M.; GOVERS, F. The genus Phytophthora anno 2012. Phytopathology, Lancaster, v.102, n.4, p.348-364, 2012.

MANG'OMBAN, S.A.; TOIT, E.S. Effect of diagonal cut surface length on graft success and growth of Mangifera indica, Persia americana, and Prunus persica. HortScience, Alexandria, v.48, n.4, p.481-484, 2013.

MASSOLA, N.S.; KRUGNER, T.L. Fungos fitopatogênicos. In: AMORIN, L.; REZENDE, J.A.M.; BERGAMIN-FILHO, A. (Ed.). Manual de fitopatologia. 4.ed. Piracicaba: Agronômica Ceres, 2011. p.149-206.
MENGE, J.A.; DOUHAN, G.W.; MCKEE, B.; POND, E.; BENDER, G.S.; FABER, B. Three new avocado rootstock cultivars tolerant to Phytophthora root rot: 'Zentmyer', 'Uzi', and 'Steddom'. HortScience, Alexandria, v.47, n.8, p.1191-1194, 2012.

MINDÊLLO-NETO, U. R.; HIRANO, E.; TELLES, C. A.; BIASI, L. A. Propagação de abacateiro cv. Fuerte por estacas herbáceas. Scientia Agraria, v.7, n.1-2, p.101104, 2006.

MICKELBART, M.V.; BENDER, G.S.; WITNEY, G.W.; ADAMS, C.; ARPAIA, M.L. Effects of clonal rootstocks on 'Hass' avocado yield components, alternate bearing, and nutrition. Journal of Horticultural Science and Biotechnology, Ashford, v.82, n.3, p.460-466, 2007.

MICKELBART, M.V.; ROBINSON, P.W.; WITNEY, G.; ARPAIA, M.L. 'Hass' avocado tree growth on four rootstocks in California. I. Yield and flowering. Scientia Horticulturae, Piracicaba, v.143, p.184-188, 2012.

MOLL, J.N.; WOOD, R. An efficient method for producing rooted avocado cuttings. Subtropical, Johannesburg, v.1, n.11, p.9-12, 1980.

MORAES, A.F.G. Desenvolvimento, produção e qualidade de frutos de abacateiro cv.'Hass' sobre dois porta-enxertos nas condições edafoclimáticas da região central do Estado de São Paulo. 2014. 55 f. Dissertação (Mestrado em Fitotecnia) - Escola Superior de Agricultura "Luiz de "Queiroz", Universidade de São Paulo, 2014.

NEVES, C.S.V.J.; MOREIRA, C.S. Avaliação de métodos para conservação de sementes de abacateiro (Persea spp.). Revista Brasileira de Fruticultura, Jaboticabal, v.13, n.1, p.117-122. 1991.

NHUT, D.T.; THI, N.N.; KHIET, B.LT.; LUAN, V.Q. Peptone stimulates in vitro shoot and root regeneration of avocado (Persea americana Mill.). Scientia Horticulturae, Amsterdam, v.115, p.124-128, 2008.

OLIVEIRA, I.V.M.; CAVALCANTE, I.H.L.; FRANCO, D.; MARTINS, A.B.G. Clonagem do abacateiro variedade "Duke 7" (Persea americana Mill.) por alporquia. Revista Brasileira de Fruticultura, Jaboticabal, v.30, n.3, p.759763. 2008a.

OLIVEIRA, I.V.M.; CAVALCANTE, I.O.L.; FRANCO, D.; MARTINS, A.B.G. Influência da época do ano no sucesso da enxertia nas variedades de abacateiro Hass e Fortuna. Revista Brasileira de Fruticultura, Jaboticabal, v.30, n.4, p.1162-1166, 2008 b. 
PETRY, H.B.; FERREIRA, B.D.P.; KOLLER, O.C.; SILVA, V.S.; SCHWARZ, S.F. Propagação de abacateiro via estacas estioladas. Bragantia, Campinas, v.71, n.1, p.15-20, 2012.

PLIEGO-ALFARO, F.; BARCELÓ-MUÑOZ.; LÓPEZGÓMEZ, R.; IBARRA-LACLETTE, E.; HERRERAESTRELLA, L.; PALOMO-RÍOS, E.; MERCADO, J.A.; LITZ, R.E. Biotechnology. In: SCHAFFER, B.A.; WOLSTENHOLME, B.N.; WHILEY, A.W. (Ed.). The avocado: botany, productions and uses. $2^{\text {nd }} \mathrm{ed}$. Homestead: CABI, 2013. cap.10, p.268-300.

RODRÍGUEZ, N.N.; CAPOTE, M.; ZAMORA, V.Cultivo in vitro del aguacatero (Persea americana Mill.). Revista Chapingo Serie Horticultura, Chapingo, v.5, p.231-237, 1999.

ROE, D.J.; CONRADIE, W.; KÖHNE, J.S. Progress with rootstock research at Merensky Technological Services. South African Avocado Growers Association Yearbook, Tzaneen, v.18, p.10-11, 1995.

SALATA, M.; SAMPAIO, A.C. Abacate: aspectos técnicos da produção. São Paulo: UNESP, Cultura Acadêmica Editora, 2008. 239p.

SALAZAR-GARCÍA, S.; GARNER, L.C.; LOVATT, C.J. Reproductive Biology. In: SCHAFFER, B.A.; WOLSTENHOLME, B.N.; WHILEY, A.W. (Ed.). The avocado: botany, productions and uses. $2^{\text {nd }}$ ed. Homestead: CABI, 2013. cap.6, p.118-167.

SCHAFFER, B.A.; GIL, P.M.; MICKELBART, M.V.; WHILEY, A.W. Ecophysiology. In: SCHAFFER, B.A.; WOLSTENHOLME, B.N.; WHILEY, A.W. (Ed.). The avocado: botany, productions and uses. $2^{\text {nd }} \mathrm{ed}$. Homestead: CABI, 2013. cap.7, p.168-199.

SILVEIRA, S.V.; SOUZA, P.V.D.; KOLLER, O.C. Propagação vegetativa de abacateiro por estaquia. Revista Brasileira de Fruticultura, Jaboticabal, v.26, n.1, p.191192, 2004.
SMITH, L.A.; DANN, E.K.; PEGG, K.G.; WHILEY, A.W. Field assessment of avocado rootstock selections for resistance to Phytophthora root rot. Australasian Plant Pathology, Collingwood, v.40, n.1, p.39-47, 2011.

SPANN, T. Huge successes achieved at avocado brainstorming 2015 \& VIII world avocado congress. From the Grove, Irvine, v.5, n.4, p.33-35, 2015.

SWINGLE, W.; ROBINSON, T. The solar propagating frame for rooting citrus and other subtropical plants. Washington: United State Departament of Agriculture, 1924. p.1-13. (Circular, 310)

VAN ROOYEN, Z. New developments in horticultural research at Westfalia, South Africa. In: WORLD AVOCADO CONGRESS, 6., 2011.Cairns. Proceedings... p.94-100.

WHILEY, A.; GIBLIN, F.; PEGG, K.; WHILEY, D. Preliminary results from avocado rootstock research in Australia. In: WORLD AVOCADO CONGRESS, 6., 2007. Viña del Mar. Proceedings... p.12-16.

WHILEY, A.W. Avocado varieties and rootstocks - a review. In: AVOCADO RESEARCH WORKSHOP, 1992 Brisbane. Proceedings.... Brisbane: Queensland Department of Primary Industries, 1992. p.15-20.

WHILEY, A.W.; WHILEY, D.G. Rootstock, improvement for the Australian avocado industry - a preliminary report. In: NEW ZEALAND AND AVOCADO GROWER'S CONFERENCE, 2005 Tauranga, Proceedings... 10 p. (Session 4)

WOLSTENHOLME, B.N. Ecology: climate and soils. In: SCHAFFER, B.A.; WOLSTENHOLME, B.N.; WHILEY, A.W. (Ed.). The avocado: botany, productions and uses. $2^{\text {nd }}$ ed. Homestead: CABI, 2013. cap.5, p.86-117.

ZIRARI, A.; LIONAKIS, S.M. Effect of cultivar, explant type, etiolation pretreatment and the age of plant material on the in vitro regeneration ability of avocado (Persea americana). Acta Horticulturae, The Hague, v.365, p.69-76, 1994. 